\title{
10. LOWER PALEOCENE-UPPER CRETACEOUS MAGNETOSTRATIGRAPHY, SITES 525, 527, 528, AND 529, DEEP SEA DRILLING PROJECT LEG $74^{1}$
}

\author{
Alan D. Chave, ${ }^{2}$ Geological Research Division, Scripps Institution of Oceanography, La Jolla, California
}

\begin{abstract}
Maestrichtian through lower Paleocene magnetostratigraphic results are presented for Holes 525A, 527, 528, and 529, DSDP Leg 74. Progressive alternating-field demagnetization of 40 pilot samples indicates stable remanence, with a median demagnetizing field of $20-40 \mathrm{mT}$ and less than $20^{\circ}$ of angular change over a $40-\mathrm{mT}$ coercive force range. Because dissolution of foraminifers and a consistent offset of the foraminiferal biostratigraphic zonation in the Cretaceous rendered them unusable for correlation, calcareous nannoplankton were employed to identify the magnetic reversals. Parts of Anomalies 25-26 and 28-32 were in evidence at the four sites. The Cretaceous/Tertiary boundary appears near the top of the reversed zone between Anomalies 29 and 30, consistent with the type section at Gubbio, Italy. Basement ages for three of the Walvis Ridge sites suggests contemporaneous formation with the nearby Angola Basin at a mid-ocean ridge. The mean paleolatitude for the interval $60-75 \mathrm{Ma}$ is $36 \pm 1^{\circ} \mathrm{S}$, some $7^{\circ}$ south of the current location.
\end{abstract}

\section{INTRODUCTION}

Upper Cretaceous (Maestrichtian-Campanian) through lower Paleocene sediments, including those from the Cretaceous/Tertiary boundary, were cored at four sites on the Leg 74 transect of the Walvis Ridge, South Atlantic Ocean. Sediment recovery ranged from 60 to $90 \%$ of the section, and three of the four holes were terminated in basaltic basement. This chapter presents the results of paleomagnetic work from Sites 525, 527, 528, and 529 . The objectives of the study were twofold: to obtain a detailed magnetostratigraphy for comparison with the biostratigraphic record and to place an upper age limit on the formation of the Walvis Ridge. The former is important in the study of the terminal Cretaceous event, and the latter has implications for the formation and evolution of aseismic ridges.

The sediment lithology is similar at all four sites, although preservation of microfossils is variable. Nannofossil and foraminifer-nannofossil chalk is the dominant sediment type in the Paleocene sections, with wellpreserved sedimentary structures and evident burrowing by macrobenthos. Farther downcore, a dramatic change in sediment lithology coincides approximately with the Cretaceous/Tertiary boundary, accompanied by a color change associated with a shift from pelagic to cyclic sedimentation and an abrupt decrease in calcium carbonate content. Below the Cretaceous/Tertiary boundary, alternating zones of chalk and mud or siltstone are persistent. Preservation of microfossils is generally poor in the Cretaceous, improved in the Paleocene, and seems to have been controlled by overburden rather than paleodepth. Further details on sediment lithology are presented in the individual site chapters (this volume), Borella (this volume), and Fuetterer (this volume).

\footnotetext{
${ }^{1}$ Moore, T., C., Jr., Rabinowitz, P. D., et al., Init. Repts. DSDP, 74: Washington (U.S, Govt. Printing Office).

2 Present address: Institute of Geophysics and Planetary Physics, A-025, University of California, San Diego, La Jolla, Ca. 92093.
}

The magnetic reversal stratigraphy of the lower $\mathrm{Pa}$ leocene and Cretaceous has been examined in uplifted marine sections exposed at Gubbio, Italy (Alvarez et al., 1977; Lowrie and Alvarez, 1977), at Umbria, Italy (Alvarez and Lowrie, 1978), in the Alps (Lowrie et al., 1980 ), and in a terrestrial section in the San Juan Basin of New Mexico (Butler et al., 1977). These studies have established an essentially complete reversal sequence for the interval, and all except the last workers place the paleontologic Cretaceous/Tertiary boundary in the reversed zone between Anomalies 29 and 30, substantiating the proposal of Sclater and others (1974). It should be noted that Butler et al. (1977) place the Cretaceous/ Tertiary boundary (located by dinosaur extinctions) near the base of Anomaly 29. The Gubbio section has been proposed as a type location for Late Cretaceous-lower Paleocene magnetostratigraphy (Alvarez et al., 1977). Of the Cretaceous-Tertiary sections recovered in DSDP holes, only Site 384 has been examined paleomagnetically, with inconclusive results (Larson and Opdyke, 1979).

\section{MEASUREMENTS}

A total of 958 samples were taken at intervals of $30-60 \mathrm{~cm}$ in undisturbed cores from Holes 525A, 527, 528 , and 529. Oriented cubic specimens $(2.3 \mathrm{~cm} \times 2.3$ $\mathrm{cm} \times 1.4 \mathrm{~cm}$ ) were cut from the working half of the split core, placed in plastic sample boxes, and capped. The collected samples were sealed in a plastic bag together with a wet sponge to prevent dessication prior to measurement. Broken pieces of core whose vertical orientation was ambiguous were ignored.

Measurements on the material from Holes 525A, 527, and 528 were made on the shipboard Digico spinner magnetometer and Schonstedt GSD-1 single-axis alternating-field demagnetizer. The Site 529 specimens were measured with a Superconducting Technology cryogenic magnetometer and a Schonstedt unit at Woods Hole Oceanographic Institution shortly after the termination 
of the leg. No thermal demagnetizer was available and no rock magnetic properties were examined.

The natural remanence of the sediments proved to be very strong and stable and yielded essentially the same stratigraphic interpretation as the demagnetized results. On the shipboard instruments 32 to 64 spins and 4 measurements sufficed to obtain a satisfactory error parameter. A reliable calibration specimen was not available on the ship, and magnetic moments will not be reported here. Results from the Site 529 material indicate natural remanent magnetization (NRM) moments of $10^{-4}$ to $10^{-7} \mathrm{amp} \mathrm{m}$.

A total of 40 pilot samples were selected for detailed alternating-field demagnetization. Each specimen was demagnetized at $2.5,5,10,15,20,25$, and $30 \mathrm{mT}$ with additional steps of 40,60 , and $100 \mathrm{mT}$ as needed $(1 \mathrm{mT}=10$ Oe). At each interval the sample was demagnetized, measured, demagnetized a second time with the sample orientation reversed, and measured once again. This was necessary both to detect machine-caused anhysteretic remanence (ARM) contamination and as a check on the magnetic stability of the sediment. The two magnetic directions were vector-averaged to yield a mean value at each demagnetization level.

Since borehole cores are not oriented azimuthally and declination is therefore meaningless, only inclination values are used for interpretation. It is not sufficient to examine inclination alone during progressive alternatingfield demagnetization, as it is the direction, not just the inclination, that should stabilize when low coercivity components of magnetization are removed. An appropriate quantity to examine is the total angular change between the NRM and demagnetized directions, calculated as the arc-cosine of the scalar product of the two vectors projected onto the unit sphere. A plot of total angular change against peak demagnetizing field should approach a constant value beyond some field value, if the specimen has been cleaned properly. Figure 1 shows all 40 pilot samples in an orthographic view as a function of depth. In general, a peak alternating field of $15-30 \mathrm{mT}$ sufficed to yield a stable endpoint. In a few cases instability was observed at high field values, usually after almost all the remanence had been destroyed.

Some of the Cretaceous material at the deeper Sites 527 and 528 consists of reddish brown stained nannofossil chalk. The contacts with surrounding uncolored sediment are indistinct, indicating a primary origin for the color with biogenic mixing rather than a postdepositional process. The color is suggestive of hematite, and the sediment does contain altered volcanic silts and clays. Detailed examination of the pilot samples suggests their separation into two populations, one associated with the stained material and the other with uncolored samples. Figure 2 shows typical demagnetization behavior for both groups. The top sample is a normal one from Hole $525 \mathrm{~A}$, with a median demagnetizing field (MDF) of $20 \mathrm{mT}$ and a total angular change of $20^{\circ}$ after $5 \mathrm{mT}$ of demagnetization. The coercive force spectrum is bimodal, with a large low coercivity component and a broad peak centered on 15-20 mT. The stained sample has a higher MDF of $40 \mathrm{mT}$ and a smaller total angular change of only $5^{\circ}$ after $20 \mathrm{mT}$ of demagnetization. The staining does not seem to affect either the stability or the NRM direction of the specimen appreciably, since adjacent uncontaminated samples show essentially the same inclination values.

Based on the results of the pilot samples for each core, a demagnetizating field of $15-30 \mathrm{mT}$ was chosen for routine use. All samples were measured, demagnetized, and measured again. Additional cleaning steps were applied as necessary. Figure 3 and 4 show the results of the downcore polarity study with depth from the seafloor, recovery, demagnetized inclination, and a polarity interpretation given. The four sites are in the southern hemisphere, where negative inclination corresponds to normal polarity. More than one opposite polarity sample was required to denote a reversal in the polarity interpretation. Reversals are occasionally noted at the top or bottom of a recovered interval and are probably the result of drilling disturbance.

Holes 525A and 527 represent the best recovery and most complete magnetic sections of the four sites. Six normal zones are recognized in each hole. The results from Sites 528 and 529 are of poorer quality because of poorer recovery and extensive slumping in the late $\mathrm{Pa}$ leocene. A 40-m-thick slump deposit appears as anomalously low inclinations at Site 528 from $330-370 \mathrm{~m}$, and there is a smaller disturbed zone from $300-310 \mathrm{~m}$ at Site 529 . This interpretation is substantiated by the paleontologic and sedimentologic data. It should be noted that Sites 528 and $\mathbf{5 2 9}$ are located at intermediate depths on the flanks of the ridge, where seismic data indicate pervasive erosion and redeposition of sediment.

\section{COMPARISON WITH BIOSTRATIGRAPHY}

In order to identify the unambiguous magnetic reversal pattern in Figures 3 and 4, we have to refer to the calcareous nannofossil and planktonic foraminiferal biostratigraphies. Preservation of foraminifers is generally poor in the Cretaceous sections, with only test fragments available in places; nannofossil preservation is somewhat better. Results of preliminary shipboard analysis indicate that foraminiferal datums in the Cretaceous are early by several million years compared to the nannofossils and the magnetic reversal pattern. For these reasons primary reference will be made to the nannofossil biostratigraphy (Manivit, this volume). Correlation of the nannofossils with the magnetic time scale is from Thierstein (1976) and Thierstein (1979 and private communication). Figure 5 shows the four magnetic sections, aligned at the Cretaceous/Tertiary boundary (see arrow) and plotted against depth together with the nannofossil biohorizons.

The paleontologic Cretaceous/Tertiary boundary occurs near the top of a reversed zone at all four sites and is marked by the extinction of the Mesozoic species Micula murus and by appearances in the Paleocene of Biantholithus sparsus, Cruciplacolithus primus, and Cruciplacolithus tenuis. The basal Tertiary planktonic foraminiferal Globigerina eugubina Zone occurs at all 


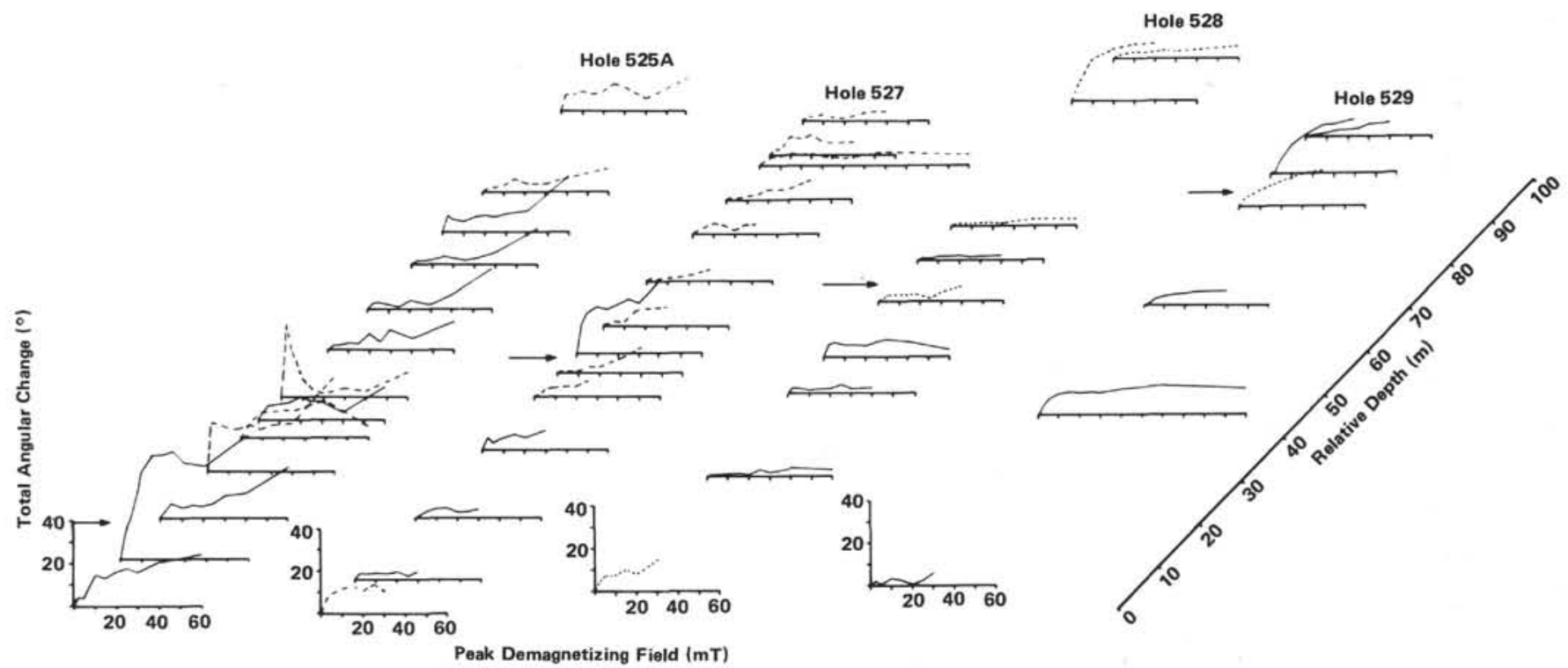

Figure 1. Orthographic plot of the total angular change from the NRM direction against peak demagnetization field as a function of depth downcore for the $\mathbf{4 0}$ pilot samples used in this study. (Horizontal arrows point to the Cretaceous/Tertiary boundary. Solid lines and dashed lines correspond to reversed and normal polarity samples, respectively.)

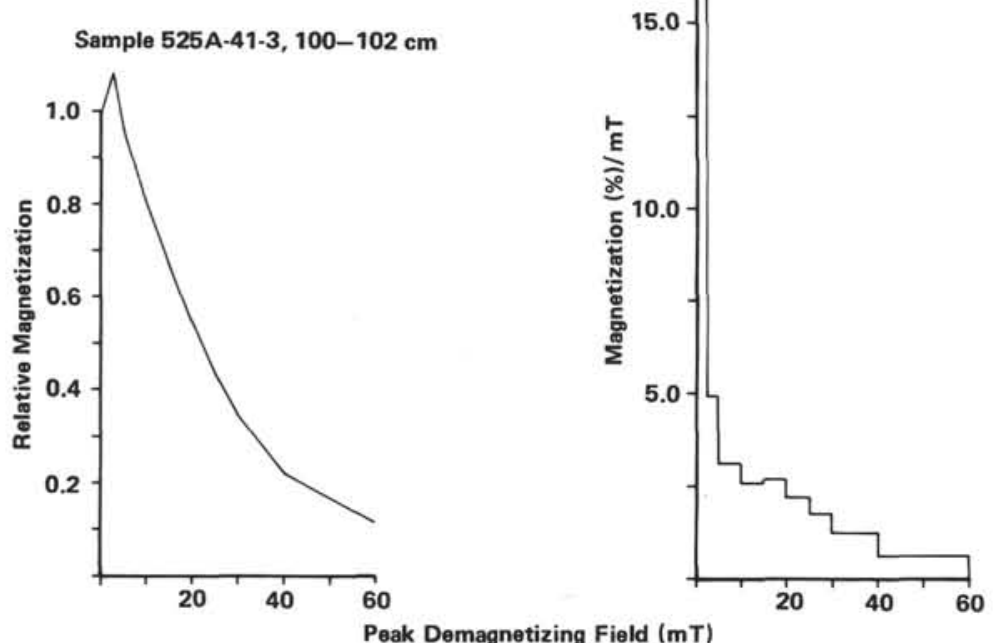

Sample 527-37-2, 74-76 cm

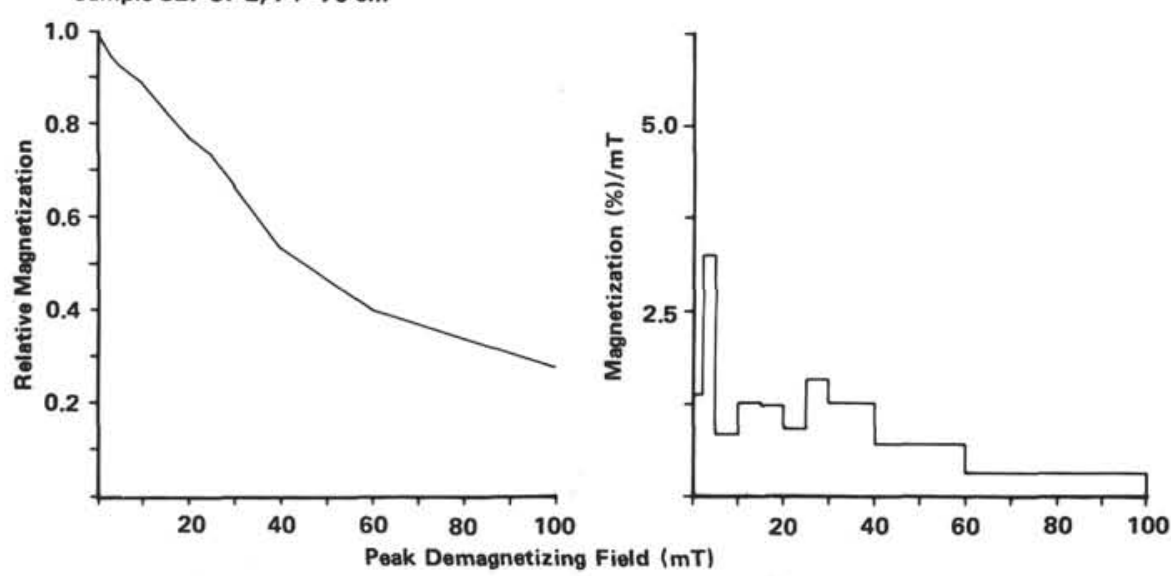

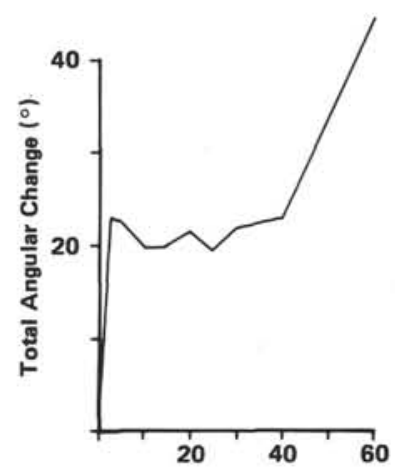

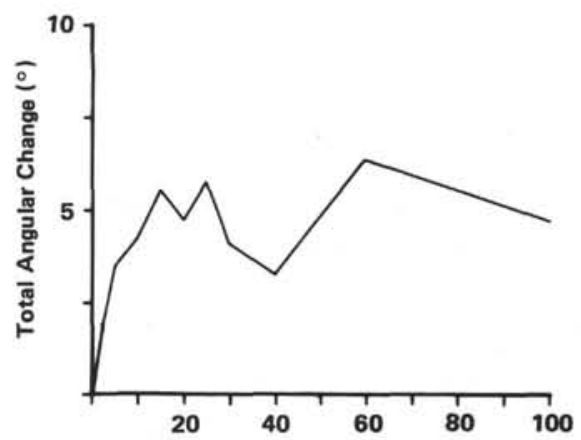

Figure 2. Typical demagnetization behavior for unstained (top) and reddish brown stained (bottom) samples. The normalized magnetic moment, coercive force spectrum, and total angular change are plotted against peak demagnetizing field. The stained sample possesses both a higher coercivity remanence and a weaker low coercivity viscous component. 


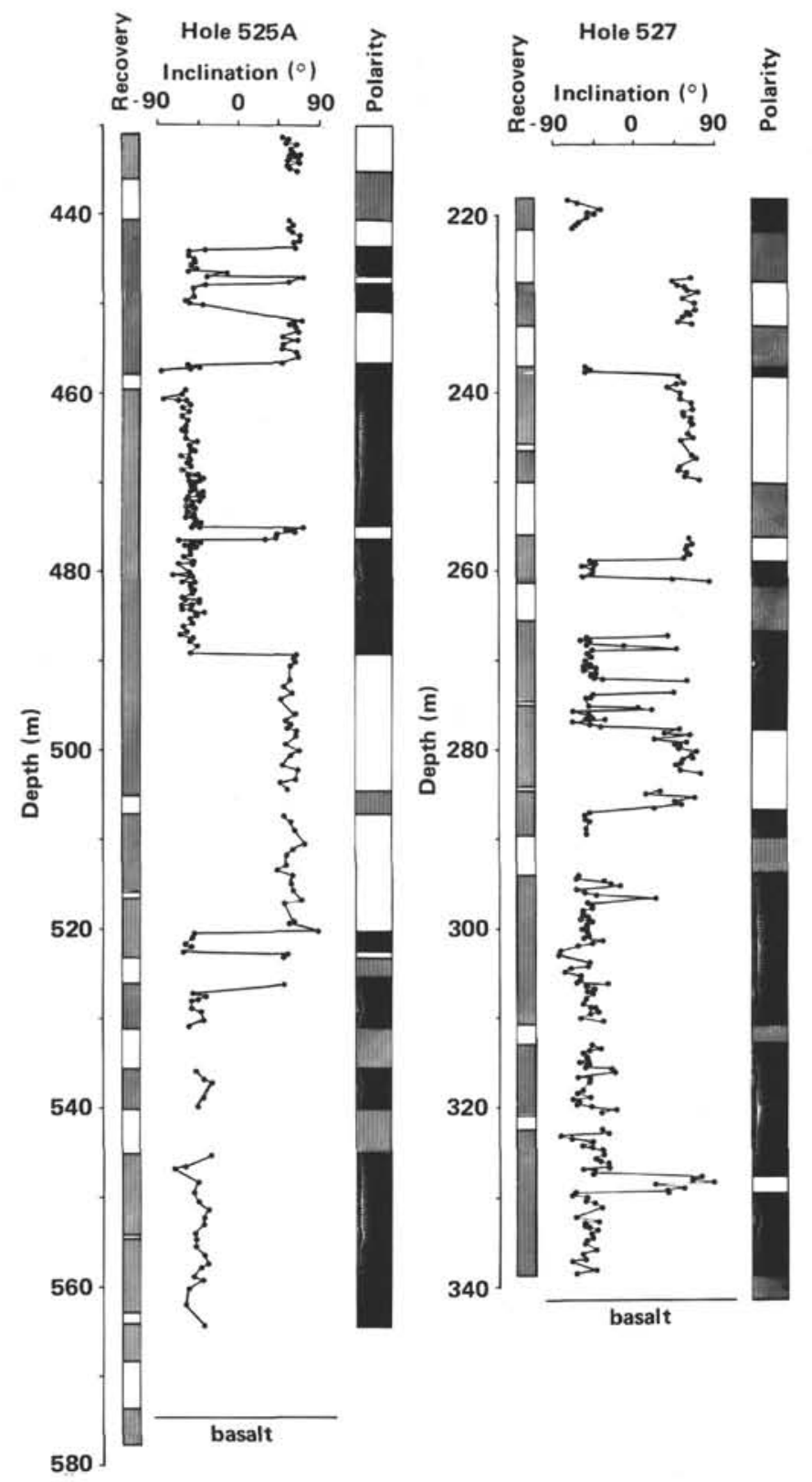

Figure 3. Magnetostratigraphic results from Holes 525A and 527, showing depth from the seafloor, recovery (shaded), inclination, and a polarity interpretation. (Normal and reversed zones are indicated by black and white shading. Stippled area indicates no polarity information owing either to poor recovery or low inclinations due to slumping.)

sites, suggesting a continuous section. By correlation to the land section results, Anomalies 29 and 30 above and below the boundary are identified.

Of the four sites drilled, 525 contains the most extensive Cretaceous section. The base of the $M$. murus Zone occurs near the middle of Anomaly 30, in agreement with the standard section. The Lithraphidites quadratus first appearance datum occurs just beneath a short reversal below Anomaly 30. The Tetralithus trifidus last appearance datum occurs low in Hole 525A, near the bottom of a long reversed interval. The Arkhangelskiella cymbiformis Zone is defined as the region between these

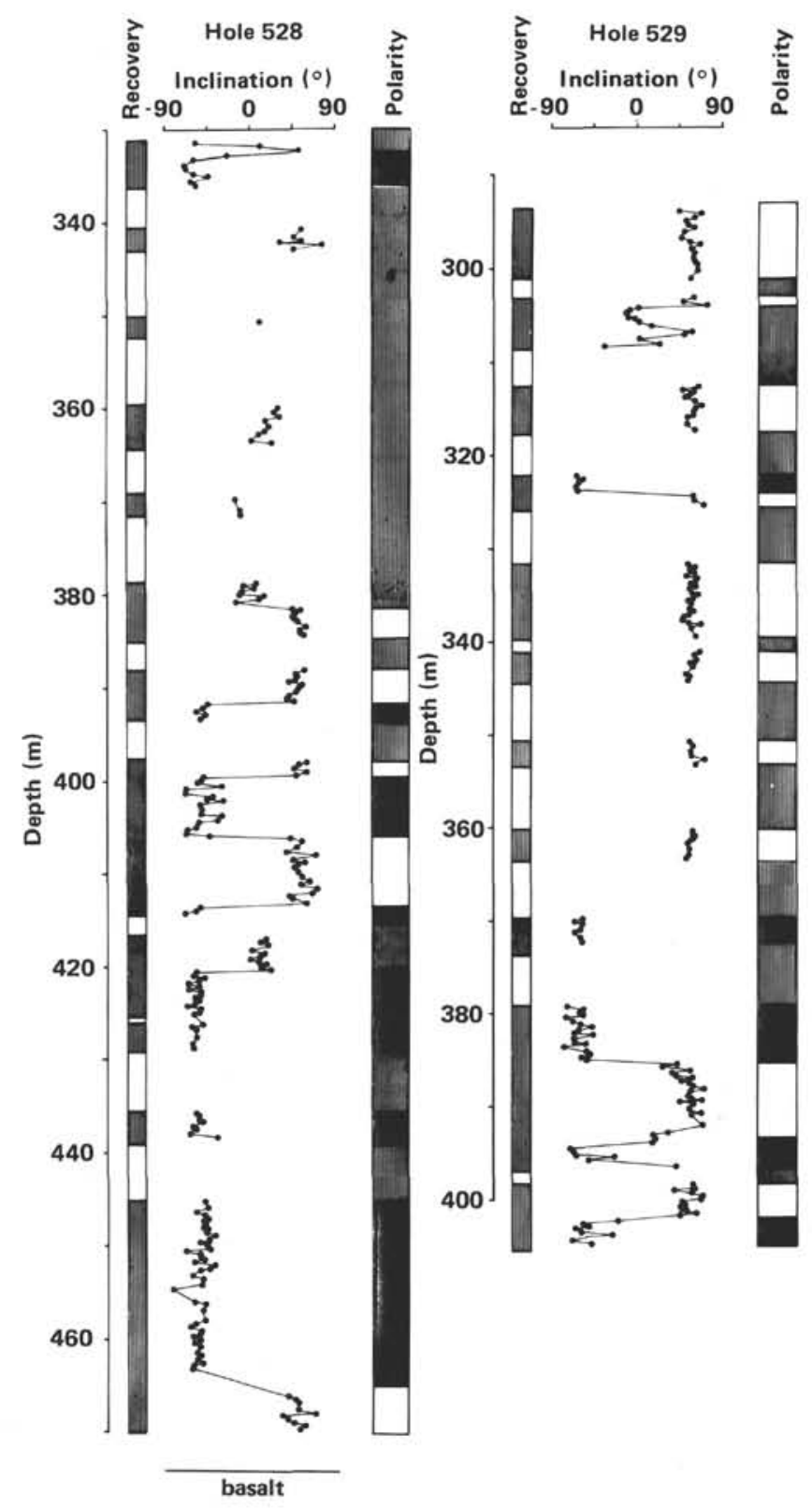

Figure 4. Magnetostratigraphic results from Holes 528 and 529. (See Fig. 3 caption for details.)

two biohorizons. The $T$. trifidus Zone extends to basement and into the intercalcated sediment in basalt. According to the ratio averaging results of Thierstein (1979), T. trifidus should vanish near the middle of Anomaly 32 , whereas $L$. quadratus should appear near the base of Anomaly 31. The logical identification of Anomaly 31 and the two parts of Anomaly 32 proceeding downward from Anomaly 30 would require both nannofossil datums to be shifted upward.

In the Paleocene of Site 525, a second normal event is observed above Anomaly 29 and is identified as Anomaly 28. If this correlation is correct, the base of the Chiasmolithus danicus Zone, which should occur near the top of Anomaly 29, is shifted upward. Above Anomaly 28, the Fasciculithus tympaniformis Zone is missing, and the Heliolithus kleinpelli first appearance datum occurs 


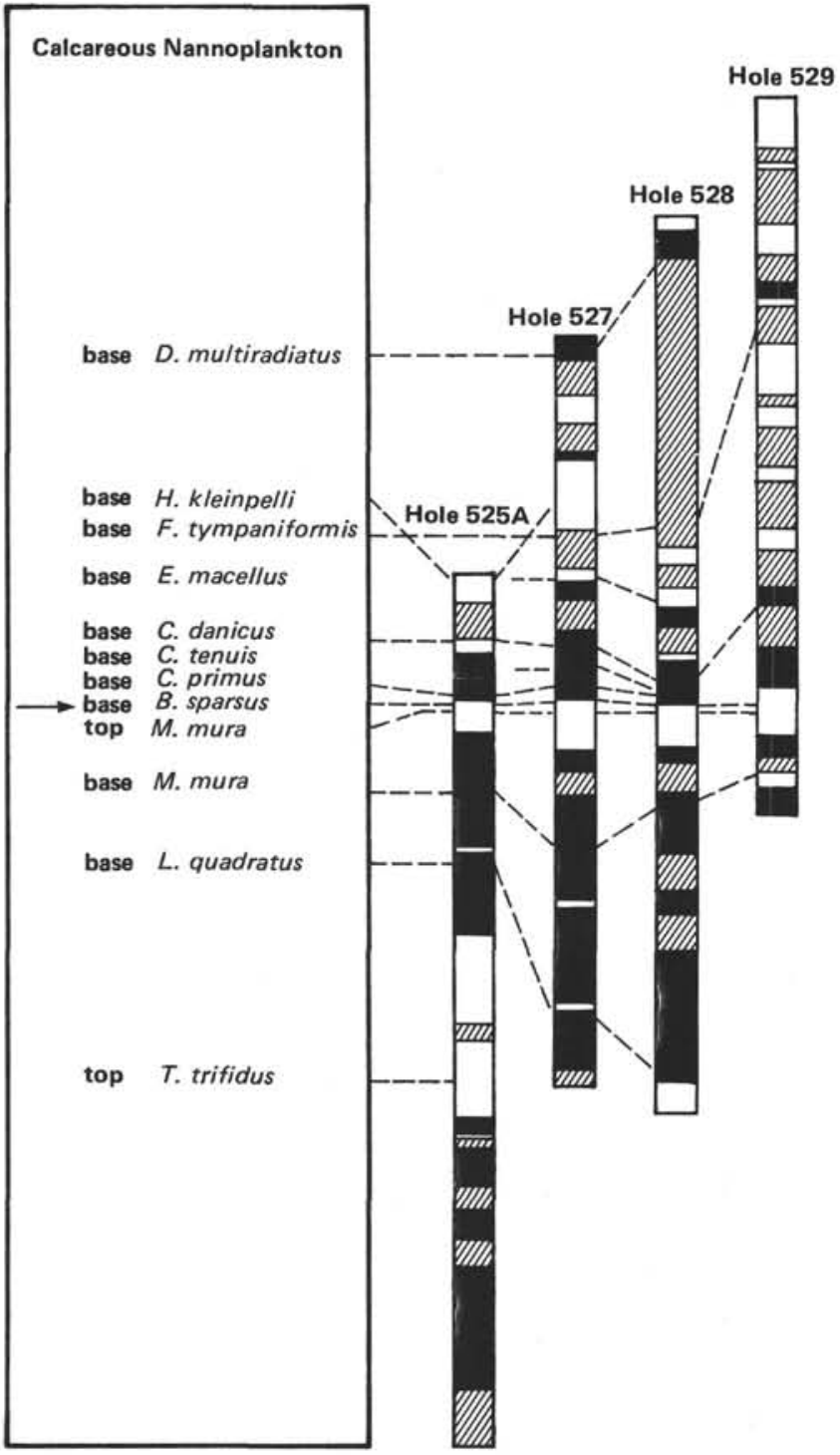

Figure 5. The four magnetic sections plotted against depth and aligned at the Cretaceous/Tertiary boundary (arrow) together with calcareous nannofossil biohorizons (from Manivit, this volume). The base of Hole 528 belongs to the $A$. cymbiformis Zone. (See text for details.)

near the top of the measured section. Anomaly 27 should be located between the $F$. tympaniformis and $H$. kleinpelli first appearances, but the absence of a normal event suggests a hiatus during that time.

At Site 527, as at 525, the $M$. murus Zone base occurs near the middle of Anomaly 30, whereas the L. quadratus first appearance datum occurs just below a short reversed event near the base of the section. By correlation to Site 525, the last normal event at this site is identified as part of Anomaly 31.

In the Paleocene, the $C$. danicus first appearance datum occurs near the top of a normal event, suggesting an expanded Anomaly 29 at Site 527 . The bases of the Ellipsolithus macellus and $F$. tympaniformis zones are visible above an incompletely recovered normal event, identifying it as part of Anomaly 28 . Anomaly 27 is not apparent between the $F$. tympaniformis and $H$. kleinpelli biohorizons in spite of good recovery, suggesting a hiatus. Discoaster multiradiatus occurs near the top of the measured section, and the part of a normal polarity event between it and the $H$. kleinpelli datum may be Anomaly 26. In addition, Anomaly 25 is visible at the top of the section.

At Site 528, the M. murus Zone base occurs below an unrecovered interval inferred to be part of Anomaly 30 . L. quafratus appears near the base of a normal event at the bottom of the section, and the reversed interval below it belongs to the A. cymbiformis Zone. This places the bottom of the hole between Anomalies 31 and 32; the short reversed interval between Anomalies 30 and 31 was not recovered.

In the Paleocene of Site 528, the $C$. danicus first appearance datum fixes the location of Anomaly 29 and the $E$. macellus datum farther up the section bounds Anomaly 28. Extensive slumping above the $F$. tympaniformis datum precludes the identification of Anomalies 26 or 27 . Anomaly 25 is apparent at the top of the measured section, above the $D$. multiradiatus biohorizon.

Hole 529 was terminated owing to time constraints shortly after the Cretaceous-Tertiary boundary was cored. The base of the $M$. murus Zone occurs near the bottom of Anomaly 30 rather than near its middle, suggesting a hiatus. The reversed and normal intervals below this indicate that the hole reached the top of Anomaly 31.

The Paleocene reversal pattern of Site 529 is difficult to correlate because of slumping and very poor recovery. C. danicus appears above an unrecovered interval and suggests an expanded Anomaly 29, as at Site 527. Above this point only a single nannofossil datum and a single reversal are available. If the biohorizon is correctly located, a high sedimentation rate from the time of Anomaly 29 to above Anomaly 28 is indicated, although Anomaly 28 is not seen. The part of a normal event above the $F$. tympaniformis datum may be Anomaly 27 .

\section{COMPARISON WITH THE MAGNETIC TIME SCALE}

Figure 6 shows the four magnetic sections, plotted against depth and aligned at the Cretaceous/Tertiary boundary, together with the Gubbio results from Alvarez et al. (1977) and the time scale of Ness et al. (1980). Anomaly identification is based on the results presented in the previous section. The Ness et al. (1980) time scale differs from the older, LaBreque et al. (1977) calibration in the Paleocene and Cretaceous in two respects: The revised potassium-argon decay constants are used, and the Paleocene/Eocene boundary is used as a tie point at the base of Anomaly 24 with an age of $54.9 \mathrm{Ma}$. This is a younger age than the one given by LaBreque et al. (1977) but is consistent with recent work in Umbria (Lowrie, Alvarez, et al., 1980) and Wyoming (Butler et al., 1981).

Anomalies 28-32 are clearly identified among Sites 525,527 , and 528. Anomaly 27 is either missing or was not cored at all sites, with the possible exception of 529 . 


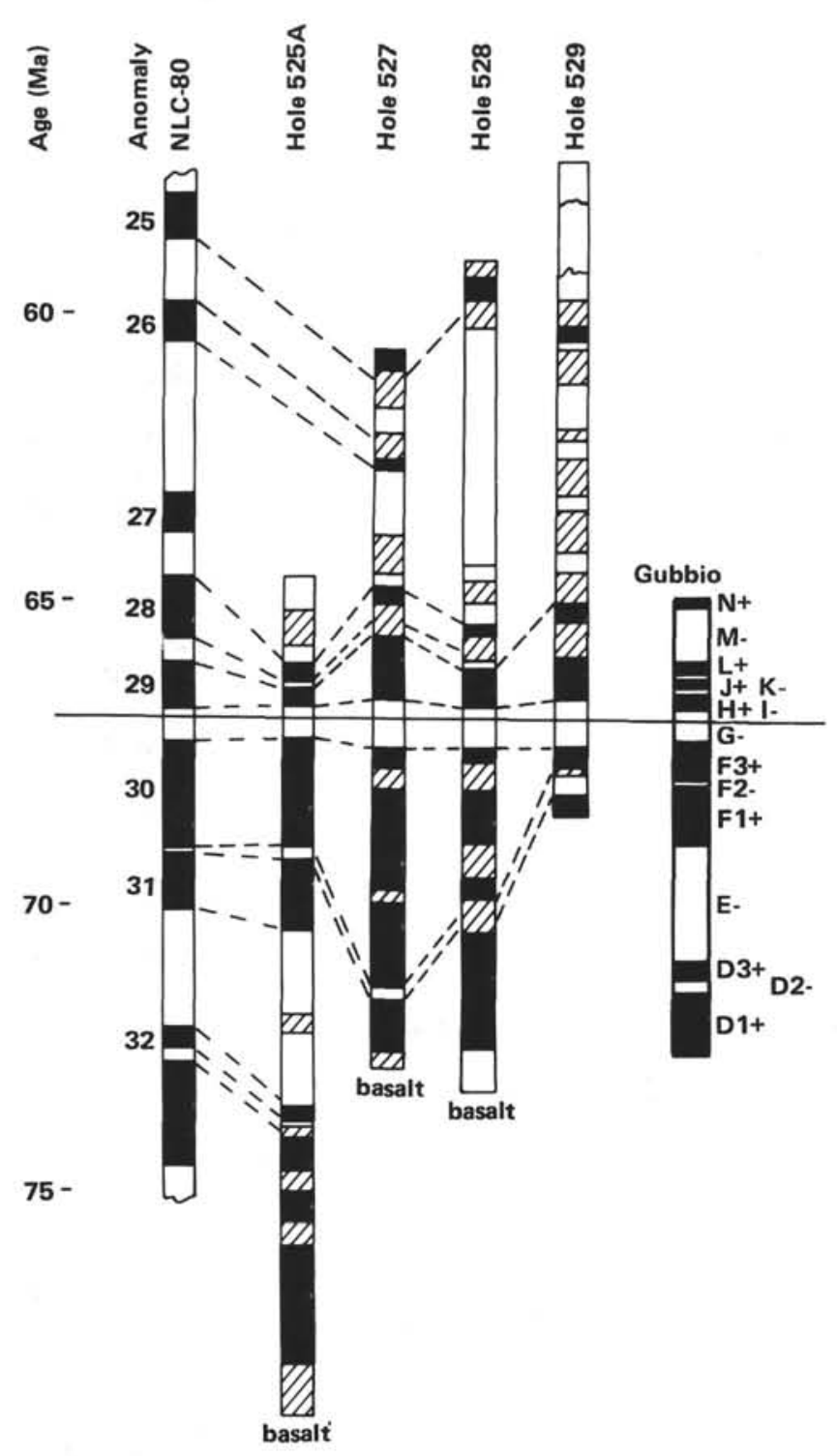

Figure 6. The four magnetic sections plotted against depth and aligned at the Cretaceous/Tertiary boundary (horizontal line), together with the time scale of Ness et al. (NLC-1980) and the Gubbio results of Alvarez et al. (1977), also plotted against depth. The short normal zone near the top of Hole 529 is identified as Anomaly 27 or 26 .

\section{DISCUSSION}

The polarity interpretation presented in this chapter is based on nannofossil biohorizons, and alternate inferences are possible. Simple pattern matching might suggest a different division of the 255-275 $\mathrm{m}$ interval at Site 527 owing to the noisy nature of the data. In this and other intervals at all four sites, short polarity changes are frequently observed at the beginning or end of undisturbed core sections and should be regarded with suspicion. Correlation with the biostratigraphy does provide anomaly identification with intersite consistency.

The offset of the foraminiferal biostratigraphic datums from the nannofossil zones precludes direct com- parison of the Leg 74 sections with the type section from Gubbio, Italy except in a qualitative way. It should be noted that the Gubbio study yielded tropical foraminiferal assemblages, in contrast to the midlatitude assemblages of the Walvis Ridge, but no nannofossils were identifiable, owing to intense dissolution and recrystallization (Premoli Silva, 1977). The Cretaceous/Tertiary boundary does occur near the top of the reversed interval between Anomalies 29 and 30, in agreement with the Gubbio results and the results from other exposed marine sequences. All the Cretaceous Gubbio events G through $\mathrm{D}$ are identified at the Leg 74 sites, and no additional events are noted. Incomplete recovery in the $\mathrm{Pa}$ leocene precludes a similar conclusion, but at least the Gubbio normal intervals $\mathrm{J}$ and $\mathrm{H}$ are visible at three of the four sites.

The Cretaceous nannofossil Lithraphidites quadratus and Tetralithus trifidus zones appear higher in the sections than would be expected from the results of Thierstein (1979). Both T. trifidus and Arkhangelskiella cymbiformis are dissolution-resistant species (Thierstein 1976); the susceptibility of $L$. quadratus is not discussed. The Chiasmolithus danicus Zone, a dissolutionsusceptible species (Thierstein and Okada, 1979), is shifted up at Site 525. It is possible that the slight inconsistencies between the standard sections and the Leg 74 results can be attributed to selective dissolution of the microfossils.

The basement age of aseismic ridges is difficult to infer from surface ship magnetic data because the crustal magnetic anomaly pattern is not generally identifiable on the structures. Rabinowitz and Simpson (1979) suggested basement ages at Sites 525, 527, and 528 of Anomalies 32, 31, and 31/32, respectively, based on extrapolation of the magnetic stripes in the Angola Basin across the ridge. The paleomagnetic results are consistent with this interpretation, suggesting that the Walvis Ridge was formed contemporaneously with the surrounding ocean basins at a mid-ocean ridge.

It is not possible to compute a paleopole position from these data, owing to the lack of declination information. The inclinations can be converted to paleolatitudes under the axial dipole hypothesis, and the averaging time of tens of millions of years justifies use of the method. Proper calculation of the mean paleolatitude and associated precision parameter, using only inclination values under the assumption of Fisherian pole positions, is given in Kono (1980). Table 1 lists the sites, polarity $(\mathrm{N}=$ normal, $\mathrm{R}=$ reversed, $\mathrm{C}=$ combined $)$, number of samples $(\mathrm{N})$, mean paleolatitude $(\lambda)$, precision parameter $(k)$, and the $95 \%$ confidence limit on $\lambda$. The mean paleolatitude for the four sites is $36 \pm 1^{\circ} \mathrm{S}$ for the interval $60-75 \mathrm{Ma}$, some $7^{\circ}$ south of the current site latitude. This is consistent with a reconstruction of the South Atlantic for $80 \mathrm{Ma}$ (Rabinowitz and LaBreque, 1979). It should be noted that the normal and reversed data yield paleolatitudes, significantly different the reversed data giving more southerly locations. This is suggestive of a northerly offset of the axial dipole during reversed intervals, as has been inferred from Tertiary 
Table 1. Site paleolatitudes from inclination values.

\begin{tabular}{lccccc}
\hline Hole & Polarity & $\begin{array}{c}\text { Number of } \\
\text { Samples } \\
(N)\end{array}$ & $\begin{array}{c}\text { Mean } \\
\text { Paleolatitude } \\
(\lambda)\end{array}$ & $\begin{array}{c}\text { Precision } \\
\text { Parameter } \\
(k)\end{array}$ & $\begin{array}{c}\text { Confidence } \\
\text { Interval } \\
(\text { A95 })\end{array}$ \\
\hline 525A & N & 153 & 33.0 & 59.1 & 1.5 \\
525A & R & 88 & 40.4 & 47.1 & 2.2 \\
$525 A$ & C & 241 & 35.8 & 45.9 & 1.4 \\
527 & N & 158 & 34.1 & 36.6 & 1.9 \\
527 & R & 80 & 36.5 & 30.4 & 2.9 \\
527 & C & 238 & 34.9 & 34.0 & 1.6 \\
528 & N & 128 & 33.0 & 52.5 & 1.7 \\
528 & R & 62 & 34.1 & 50.1 & 2.6 \\
528 & C & 190 & 33.3 & 51.5 & 1.4 \\
529 & N & 42 & 39.8 & 28.3 & 4.2 \\
529 & R & 121 & 40.6 & 52.4 & 1.8 \\
529 & C & 163 & 40.4 & 42.6 & 1.7 \\
All & N & 481 & 33.9 & 47.8 & 0.9 \\
All & R & 351 & 38.5 & 39.5 & 1.2 \\
All & C & 832 & 35.9 & 41.6 & 0.8 \\
\hline
\end{tabular}

Note: $\mathrm{N}=$ normal, $\mathrm{R}=$ reversed, $\mathrm{C}=$ combined.

data (Wilson, 1971). It is interesting to see that the precision parameter ranges between 30 and 50 , as has been observed in Quaternary and Tertiary lava flows, and is attributed to secular variation of the geomagnetic field (McElhinny and Merrill, 1975).

\section{ACKNOWLEDGMENTS}

Bill Mills of fered many useful suggestions for sampling operations during Leg 74 and tirelessly collected specimens for paleomagnetic measurement throughout the cruise. Chuck Denham provided access to the cryogenic magnetometer at Woods Hole Oceanographic Institution. Hans Thierstein explained some of the details of nannofossil biostratigraphy during several fruitful sessions. The manuscript was reviewed by C. R. Denham, H. R. Thierstein, and E. L. Winterer. The author was supported by a Geological Research Division/Scripps Industrial Associates postdoctoral fellowship.

\section{REFERENCES}

Alvarez, W., Arthur, M. A., Fischer, A. G., Lowrie, W., Napoleone, G., Premoli Silva, I., and Roggenthen, W. M., 1977. Upper Cretaceous-Paleocene geomagnetic reversal time scale. Geol. Soc. Am. Bull., 88:383-389.

Alvarez, W., and Lowrie, W., 1978. Upper Cretaceous paleomagnetic stratigraphy at Moria (Umbrian Appenines, Italy): Confirmation of the Gubbio section. Geophys. J. R. Astron. Soc., 55:1-17.

Butler, R. F., Gingerich, P. D., and Lindsay, E. H., 1981. Magnetic polarity stratigraphy and biostratigraphy of Paleocene and lower Eocene continental deposits, Clark's Fork Basin, Wyoming. $J$. Geol., 89:299-316.
Butler, R. F., Lindsay, E. H., Jacobs, L. L., and Johnson, N. R., 1977. Magnetostratigraphy of the Cretaceous-Tertiary boundary in the San Juan Basin, New Mexico. Nature, 267:318-323.

Kono, M., 1980. Statistics of paleomagnetic inclination data. $J$. Geophys. Res., 85:3878-3882.

LaBreque, J. L., Kent, D. V., and Cande, S. C., 1977. Revised magnetic polarity time scale for Late Cretaceous and Cenozoic time. Geology, 5:330-335.

Larson, P. D., and Opdyke, N. D., 1979. Paleomagnetic results from early Tertiary/Late Cretaceous sediments of Site 384. In Tucholke, B. E., Vogt, P. R., et al., Init. Repts. DSDP, 43: Washington (U.S. Govt. Printing Office), 785-788.

Lowrie, W., and Alvarez, W., 1977. Late Cretaceous geomagnetic polarity sequence: Detailed rock and paleomagnetic studies of the Scaglia Rossa limestone at Gubbio, Italy. Geophys. J. R. Astron. Soc., 51:561-581.

Lowrie, W., Alvarez, W., Napoleone, G., Perch-Nielsen, K., Toumarkine, M., and Premoli Silva, I., 1980. Paleogene magnetic reversal stratigraphy in Umbrian pelagic carbonate rocks. Eos, 61:144. (Abstract)

Lowrie, W., Channell, J. E. T., and Alvarez, W., 1980. A review of magnetic stratigraphy investigations in Cretaceous pelagic carbonate rocks. J. Geophys. Res., 85:3597-3605.

McElhinny, M., and Merrill, R., 1975. Geomagnetic secular variation over the past 5 m.y.. Rev. Geophys. Space Phys., 13:687-708.

Ness, G., Levi, S., and Couch, R., 1980. Marine magnetic anomaly timescales for the Cenozoic and Late Cretaceous: A precis, critique, and synthesis. Rev. Geophy. Space Phys., 18:753-770.

Premoli Silva, I., 1977. Upper Cretaceous-Paleocene magnetic stratigraphy at Gubbio, Italy II., biostratigraphy. Geol. Soc. Am. Bull., 88:371-374.

Rabinowitz, P. D., and LaBreque, J., 1979. The Mesozoic South Atlantic Ocean and evolution of its continental margins. J. Geophys. Res., 84:5973-6002.

Rabinowitz, P. D., and Simpson, E. S. W., 1979. Results of IPOD site surveys aboard R/V Thomas B. Davie: Walvis Ridge Survey, L-DGO Tech. Rept.

Sclater, J. G., Jarrard, R. D., McGowran, B., and Gartner, S., Jr., 1974. Comparsion of the magnetic and biostratigraphic time scales since the Late Cretaceous. In von der Borch, C. C., Sclater, J. G., et al., Init. Repts. DSDP, 22: Washington (U.S. Govt. Printing Office), 381-386.

Thierstein, H. R., 1976. Mesozoic and calcareous nannoplankton biostratigraphy of marine sediments. Mar. Micropaleont., 1:325-362. 1979. Ratio averaging as a quantitative chronostratigraphic tool. Geol. Soc. Am. Abstracts with Programs, 11/7:527. (Abstract)

Thierstein, H. R., and Okada, H., 1979. The Cretaceous/Tertiary boundary event in the North Atlantic. In Tucholke, B. E., Vogt, P. R., et al., Init. Repts. DSDP, 43: Washington (U.S. Govt. Printing Office), 601-616.

Wilson, R. T., 1971. Dipole offset-the time-average paleomagnetic field over the past 25 million years. Geophys. J. R. Astron. Soc., 22:491-504. 